\title{
Gene expression and promoter methylation of porcine uncoupling protein 3 gene
}

\author{
Ruiyi Lin ${ }^{1, a}$, Weimin Lin ${ }^{1, a}$, Qiaohui Chen ${ }^{1}$, Jianchao Huo ${ }^{1}$, Yuping Hu${ }^{1}$, \\ Junxiao $\mathrm{Ye}^{1}$, Jingya $\mathrm{Xu}^{1}$, and Tianfang $\mathrm{Xiao}^{1, *}$
}

\begin{abstract}
* Corresponding Author: Tianfang Xiao Tel: +86-591-83789157, Fax: +86-591-83789729, E-mail: tfxia@@fafu.edu.cn
\end{abstract}

${ }^{1}$ College of Animal Science, Fujian Agriculture and Forestry University, Fuzhou, Fujian 350002, China

a These authors contributed equally to this work.

ORCID

Tianfang Xiao

https://orcid.org/0000-0001-5116-7642

Submitted Feb 6, 2018; Revised May 23, 2018; Accepted Jun 27, 2018
Objective: Uncoupling protein 3 gene (UCP3) is a candidate gene associated with the meat quality of pigs. The aim of this study was to explore the regulation mechanism of UCP3 expression and provide a theoretical basis for the research of the function of porcine UCP3 gene in meat quality.

Methods: Bisulfite sequencing polymerase chain reaction (PCR) and quantitative real-time PCR (Q-PCR) were used to analyze the methylation of UCP3 5'-flanking region and UCP3 mRNA expression in the adipose tissue or skeletal muscle of three pig breeds at different ages (1, 90, 210-day-old Putian Black pig; 90-day-old Duroc; and 90-day-old Dupu).

Results: Results showed that two cytosine-guanine dinucleotide $(\mathrm{CpG})$ islands are present in the promoter region of porcine UCP3 gene. The second CpG island located in the core promoter region contained $9 \mathrm{CpG}$ sites. The methylation level of $\mathrm{CpG}$ island 2 was lower in the adipose tissue and skeletal muscle of 90-day-old Putian Black pigs compared with 1-dayold and 210-day-old Putian Black pigs, and the difference also existed in the skeletal muscle among the three 90-day-old pig breeds. Furthermore, the obvious changing difference of $U C P 3$ mRNA expression was observed in the skeletal muscle of different groups. However, the difference of methylation status and expression level of UCP3 gene was not significant in the adipose tissue.

Conclusion: Our data indicate that $U C P 3$ mRNA expression level was associated with the methylation status of $U C P 3$ promoter in the skeletal muscle of pigs.

Keywords: Pig; Uncoupling Protein 3 (UCP3) Gene; Meat Quality; Methylation; Expression

\section{INTRODUCTION}

With the improvements in living standards, people tend to be interested in eating high-quality pork. Improvement of porcine meat quality has become a priority when it comes to pig breeding and is also one of the ways in which breeding enterprises can earn more [1]. Uncoupling protein 3 gene (UCP3) was reported to wield a significant influence on fat deposition in pigs, which is an important factor affecting meat quality, especially influencing the juiciness, tenderness, and color of pork [2-4]. UCP3 gene belongs to the mitochondrial anion carrier gene family, mainly involved in the uncoupling effect of mitochondrial respiratory chain and has an important impact on separating oxidative phosphorylation from the synthesis of ATP as energy which is anticipated as heat $[5,6]$.

Porcine UCP3 gene is located on chromosome 9p21-p24 with the full-length open reading frame of $927 \mathrm{bp}$, coding 308 amino acids [7,8]. The chromosome location of UCP3 gene is consistent with the notion that numerous quantitative trait loci (QTLs) related to carcass and meat quality traits were located on SSC9 in swine (https://www.animalgenome.org/cgibin/QTLdb/SS/viewmap). In a study on pigs at high ambient temperature, it was reported 
that the UCP3 expression was upregulated in the muscle [9]. UCP3 mRNA expression in adipose tissue was found to be differentially associated with leptin between groups according to the birth weight of piglets [10]. In mice, the overexpression of $U C P 3$ protected against the accumulation of triglyceride in both muscle and adipose tissue [11]. Lin et al [12] discovered that UCP3 could mediate heat production in cold-resistant pigs to adapt to cold environments; furthermore, eight dominant pig breeds from China could be classified into coldsensitive and cold-resistant breeds based on the sequence of UCP3.

The polymorphisms of UCP3 gene have been reported to be associated with meat quality traits in pigs. Cieslak et al [13] found a novel missense substitution in the UCP3 and the polymorphism of $U C P 3$ (g.946C $>\mathrm{T}$ ) was potentially associated with porcine abdominal fat weight. One 9-base continuous mutated site in 3'UTR of pig UCP3 gene was screened, and the site was identified in significantly close association with the backfat thickness at the sixth and seventh rib [14]. Tu et al [15] detected three coding-region single nucleotide polymorphisms in UCP3 gene and found that one of the mutations may have a significant effect on several carcass and meat quality traits.

However, few studies have focused on the UCP3 5'-flanking or promoter region, the correlation between promoter cytosineguanine dinucleotide $(\mathrm{CpG})$ island methylation status, and UCP3 mRNA expression. In this study, bisulfite sequencing polymerase chain reaction (PCR) was used to investigate the methylation status of the UCP3 gene promoter and quantitative real-time PCR (Q-PCR) was used to measure UCP3 mRNA expression in the adipose tissue or skeletal muscle of three pig breeds at different ages.

\section{MATERIALS AND METHODS}

\section{Animals and tissues}

All animal procedures were conducted according to the Regulations for the Administration of Affairs Concerning Experimental Animals (Ministry of Science and Technology, China, revised in July 2013) and approved by the Experimen- tal Animal Care and Use Committee of Fujian Agriculture and Forestry University (Fuzhou, Fujian, China).

Putian Black pig is a quality native breed in Fujian province and included in the list of National Livestock and Poultry Genetic Resources Protection of China. Dupu pig is a hybrid of Duroc $\times$ Putian Black pig. All pigs (1, 90, and 210-day-old Putian Black pigs; 90-day-old Duroc; and 90-day-old Dupu, $\mathrm{n}=4$ per group) included in the study were euthanized at a commercial slaughterhouse. The adipose and skeletal muscle were removed immediately, washed briefly with phosphatebuffered saline, rapidly frozen in liquid nitrogen, and stored at $-80^{\circ} \mathrm{C}$.

\section{Bioinformatic analysis}

Analysis and identification of the putative promoter region in the $5^{\prime}$-flanking of the UCP3 gene were performed using the following online tools: Promoter Scan (http://www-bimas.cit. nih.gov/molbio/proscan) [16], Promoter 2.0 (http://www.cbs. dtu.dk/services/Promoter/) [17], NNPP (http://www.fruitfly. org/seq_tools/promoter.html) [18] and AliBaba2.1 (http://generegulation.com/pub/programs/alibaba2/index.html). The CpG island predicting and primer designing were conducted by MethPrimer (http://www.urogene.org/cgi-bin/methprimer/ methprimer.cgi) [19].

\section{Methylation detection of $\mathrm{CpG}$ island}

Genomic DNA was extracted from the samples by standard phenol/chloroform procedure and modified using the EZ DNA Methylation-Gold Kit (ZYMO Research, Irvine, CA, USA) according to the manufacturer's instructions.

The reaction mixture for the analysis included $20 \mu \mathrm{L}$ of PCR product containing $100 \mathrm{ng}$ genomic DNA, $2 \mu \mathrm{L}$ of $10 \times \mathrm{PCR}$ buffer, $150 \mu \mathrm{M}$ dNTPs, $1 \mu \mathrm{M}$ of each PCR primer (Table 1), $1 \mathrm{U}$ Taq DNA polymerase (TaKaRa, Tokyo, Japan), and sterilized distilled water up to $20 \mu \mathrm{L}$. The amplifying conditions of PCR for normal DNA were $94^{\circ} \mathrm{C}$ for $5 \mathrm{~min}$, followed by 40 cycles of $94^{\circ} \mathrm{C}$ for $30 \mathrm{~s}, 51^{\circ} \mathrm{C}$ for $30 \mathrm{~s}, 72^{\circ} \mathrm{C}$ for $30 \mathrm{~s}$, and $72^{\circ} \mathrm{C}$ for $10 \mathrm{~min}$. The annealing temperature used to amplify the bisulfite-treated DNA was $58^{\circ} \mathrm{C}$. The PCR products were visualized by electrophoresis in $1.5 \%$ agarose gel electrophoresis

Table 1. Primer pairs used for PCR amplification

\begin{tabular}{|c|c|c|c|}
\hline Primer name & Primer sequences $\left(5^{\prime}-3^{\prime}\right)$ & Length (bp) & $\operatorname{Tm}\left({ }^{\circ} \mathrm{C}\right)$ \\
\hline \multirow[t]{2}{*}{ UCP3 normal primer } & F:AGTTTTAGTTTATGTG & 426 & 51 \\
\hline & R:ACTTACCCTCAATATT & & \\
\hline \multirow[t]{2}{*}{ UCP3 BSP primer } & F:TTGTGGTATATGGAGGTTTTTAGG & 151 & 58 \\
\hline & R: CTTCACTCAATAAATTAAAAATCCAAC & & \\
\hline \multirow[t]{2}{*}{ UCP3 Q-PCR primer } & F:AGTGGATGTGGTGAAGACCC & 142 & 60 \\
\hline & R: TTCCCAAGCGCAAAAAGGAAG & & \\
\hline \multirow[t]{2}{*}{$\beta$-actin Q-PCR primer } & F:TCTGGCACCACACCTTCT & 114 & 60 \\
\hline & R:TGATCTGGGTCATCTTCTCAC & & \\
\hline
\end{tabular}

$P C R$, polymerase chain reaction; UCP3, uncoupling protein 3; BSP, bisulfite sequencing PCR; $Q-P C R$, quantitative real-time PCR. 
and purified by MiniBEST Agarose Gel DNA Extraction Kit (TaKaRa, Japan).

The expected PCR fragment was cloned and inserted into the pMD18-T vector. The recombinant clones were used to transform Trans5a Chemically Competent Cell (TransGen Biotech, Beijing, China). The positive recombinant clones were selected on Luria-Bertani medium containing $60 \mu \mathrm{g} / \mathrm{mL}$ ampicillin and confirmed by PCR. Five randomly selected positive recombinant clones from each individual were sequenced through a commercial sequencing facility (Sangon, Shanghai, China). The sequencing results were analyzed using QUMA software [20].

\section{RNA isolation and reverse transcription}

Total RNA was extracted from frozen tissues using TRIzol reagent (Invitrogen, Carlsbad, CA, USA) according to the manufacturer's protocol. The concentration and quality of the isolated RNA were determined using Nanodrop 2000 (Thermo Fisher Scientific, Leicester, UK) and denatured gel electrophoresis. Reverse transcription polymerase chain reaction (RT-PCR) was conducted using PrimeScript RT reagent Kit with gDNA Eraser (TaKaRa, Japan), containing oligo (dT), random primers and gDNA Eraser. After treating $1 \mu \mathrm{g}$ RNA with gDNA Eraser, the reverse transcription reaction was carried out at $37^{\circ} \mathrm{C}$ for $15 \mathrm{~min}, 85^{\circ} \mathrm{C}$ for $5 \mathrm{~s}$, and $4^{\circ} \mathrm{C}$ for $2 \mathrm{~min}$.

\section{Quantitative real-time polymerase chain reaction} analysis

Quantitative real-time PCR (Q-PCR) was performed using an ABI Prism 7500 sequence-detection system (Applied Biosystems, Foster City, CA, USA) with SYBR Green Realtime PCR Master Mix (Toyobo, Osaka, Japan), under the manufacturer's instructions.

The UCP3 fragment was amplified using the primers listed in Table 1 and the $\beta$-actin primers were used as internal control. The primers for Q-PCR were designed by Lin et al [12] and Erkens et al [21]. All PCRs were performed in triplicate and the expression level of $U C P 3$ was quantified relative to the expression of $\beta$-actin by employing the $2^{-\Delta \Delta C \mathrm{Ct}}$ value method [22].

\section{Data analysis}

Differences between groups were performed with one-way analysis of variance and least significant difference test (V19.0, SPSS Inc., Chicago, IL, USA). Methylation levels and mRNA expression were analyzed by Pearson's correlation.

\section{RESULTS}

Bioinformatics analysis of the porcine UCP3 promoter Analysis of the porcine UCP3 gene $5^{\prime}$-flanking region (2 kb upstream of the initiation codon) revealed that the core promoter region is located between nucleotides -870 and -550 and the $2 \mathrm{~kb}$-fragment contains two CpG islands: $-1,603$ to $-1,501$ and -910 to -777 (Figure 1). Here, the second CpG island located within the putative promoter region was speculated to play a role in regulating gene expression. Several putative transcription factor binding sites were also identified in this CpG island, including Sp1 transcription factor, neurofibromin 1, CCAAT enhancer binding protein beta, transcription factor AP-2 alpha, CCAAT enhancer binding protein alpha, and organic cation/carnitine transporter 1 . Therefore, primers were designed to amplify the fragment containing $9 \mathrm{CpG}$ sites of $\mathrm{CpG}$ island 2.

\section{Methylation status of the porcine UCP3 promoter}

The PCR products of normal and bisulfite-treated DNA were analyzed by using $1.5 \%$ agarose gel electrophoresis, and the positive recombinant clones were sequenced by Sangon Biotech. By comparative sequencing of the putative UCP3 promoter region, we identified two novel single nucleotide polymorphisms $(-882 \mathrm{~A} / \mathrm{T},-852 \mathrm{G} / \mathrm{A})$ in the $5^{\prime}$-flanking region of

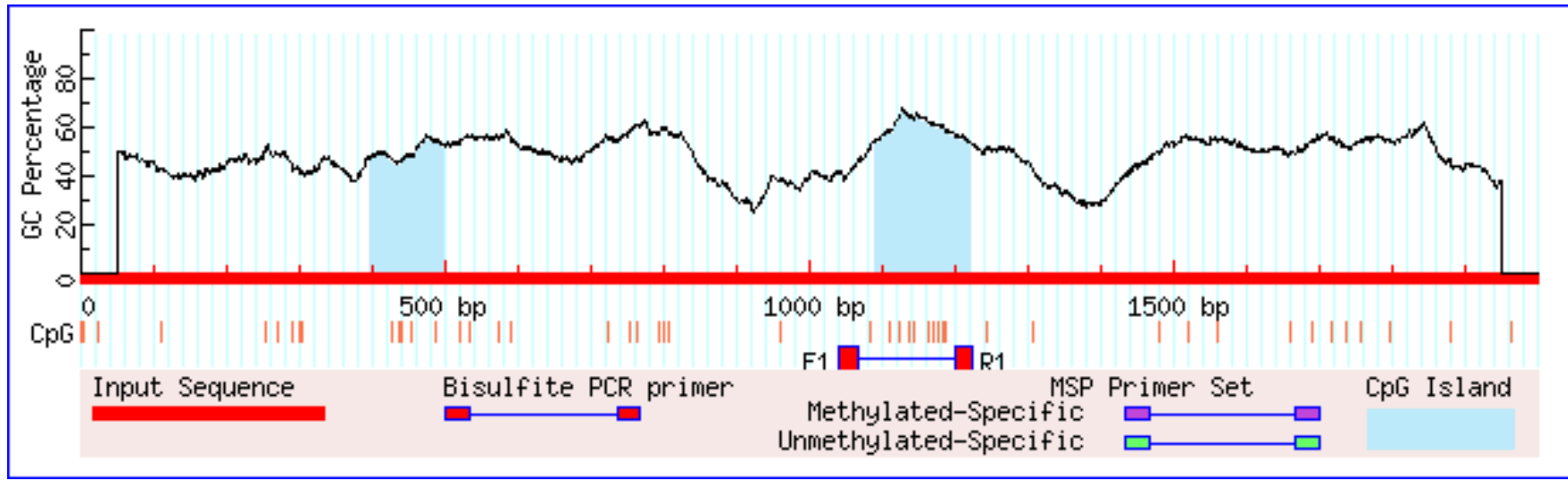

Figure 1. Bioinformatics analysis of the CpG island and primer design for bisulfite sequencing PCR of the porcine UCP3 gene. The blue region is the CpG island. CpG, cytosine-guanine dinucleotide; PCR, polymerase chain reaction; UCP3, uncoupling protein 3. 
porcine UCP3.

The methylation status of the putative UCP3 promoter region was examined in the adipose tissue and skeletal muscle of Putian Black pig at three different ages (Figure 2). Data in Table 2 showed that the degree of methylation in 90-day-old Putian Black pig was lower compared with the other two ages in skeletal muscle and adipose tissue. However, the changing of methylation status did not reach the statistical significance level in adipose tissue. Furthermore, we measured the methylation level of skeletal muscle in other two 90-day-old pig breeds (Duroc, 19.44\% $\pm 5.56 \%$, Dupu, 11.11\%, Supplementary Figure S1). The methylation level in Dupu was lower than that in Duroc $(\mathrm{p}<0.05)$, and there was no significant difference between that of Dupu and Putian Black pig.

\section{mRNA expression level of UCP3 gene}

The relative expression level of UCP3 in the skeletal muscle of the Putian Black pig increased to the highest at 90 days ( $\mathrm{p}<$ 0.01 ) and then decreased at 210 days (Figure 3 ). However, the

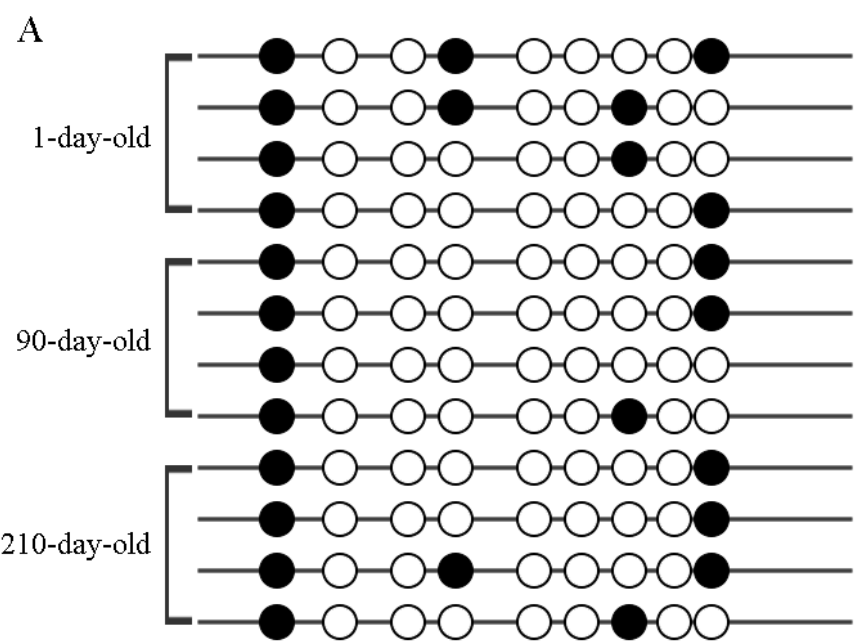

Table 2. Methylation status of the UCP3 gene in Putian Black pig at different ages

\begin{tabular}{lccc}
\hline Tissue & $\begin{array}{c}\mathbf{1} \text { day } \\
(\mathbf{n}=\mathbf{4})\end{array}$ & $\begin{array}{c}\mathbf{9 0} \text { days } \\
(\mathbf{n}=\mathbf{4})\end{array}$ & $\begin{array}{c}\mathbf{2 1 0} \text { days } \\
(\mathbf{n}=\mathbf{4})\end{array}$ \\
\hline Adipose (\%) & $27.78 \pm 6.42$ & $19.44 \pm 5.56$ & $25.00 \pm 5.56$ \\
Skeletal muscle (\%) & $25.00 \pm 5.56^{\mathrm{a}}$ & $13.89 \pm 5.56^{\mathrm{b}}$ & $27.78 \pm 6.42^{\mathrm{a}}$ \\
\hline
\end{tabular}

UCP3, uncoupling protein 3.

Values are means \pm standard error.

${ }^{\text {ab }}$ Within the same rows, values with different superscripts letters differ $(p<0.05)$.

UCP3 mRNA expression level was not different in the adipose tissue of different ages. Moreover, the expression level of UCP3 in skeletal muscle was the highest in Dupu pig and the lowest in Duroc at 90-day-old (Figure 4). Pearson's correlation analysis showed that the methylation status of the CpG island correlated negatively with UCP3 expression in skeletal muscle ( $\mathrm{r}=-0.82$ or $-0.72 ; \mathrm{p}<0.01$ ); with significant correlation coefficients for CpG_9 in Putian Black pig at three stages $(\mathrm{r}=$ $-0.632 ; \mathrm{p}<0.05)$.

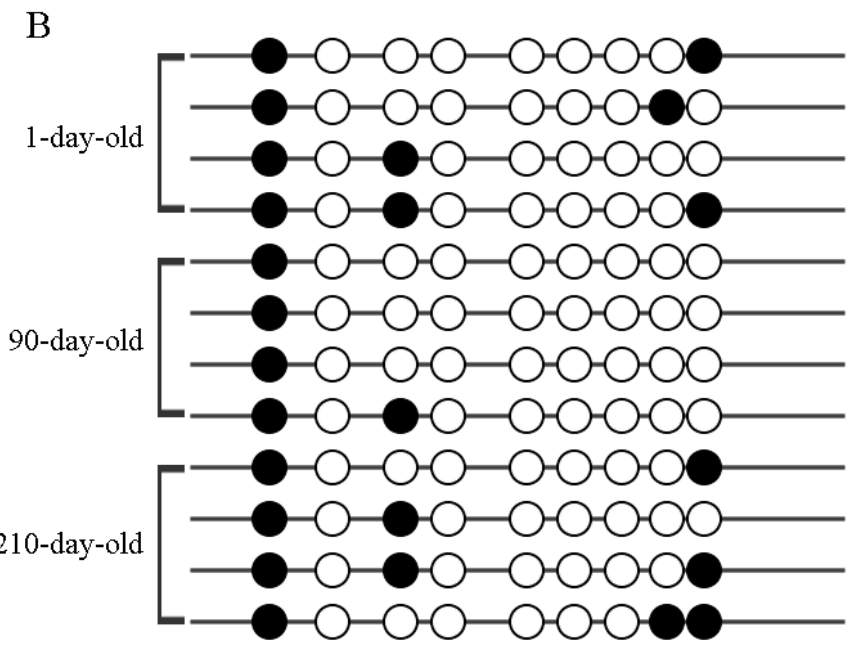

Figure 2. The methylation pattern of $\mathrm{CpG}$ island 2 of each Putian Black pig at different ages. (A) Adipose tissue, (B) skeletal muscle. Every circle represents a CG, black circles mean methylated CG, and white circles mean unmethylated CG. CpG and CG, cytosine-guanine dinucleotide.

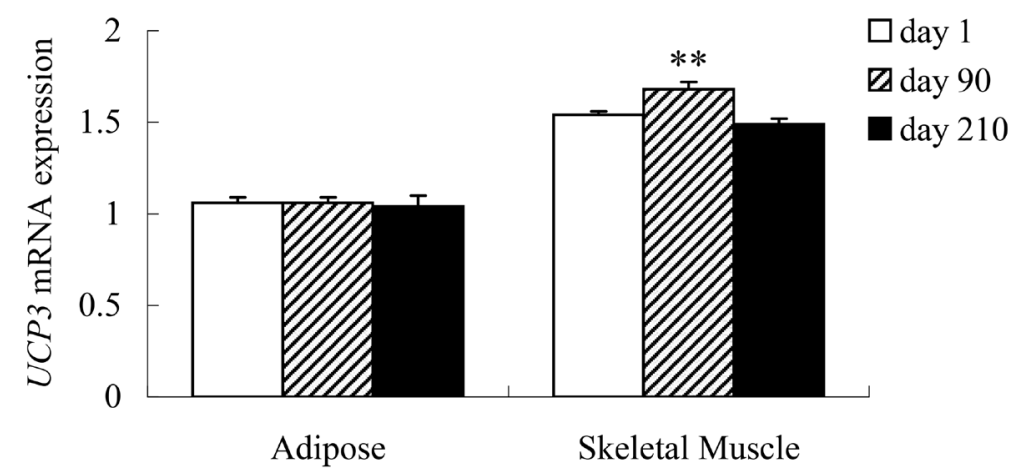

Figure 3. Differentiation of UCP3 mRNA expression in adipose tissue and skeletal muscle between different ages. Values are means with their standard errors. Significant differences between groups in the same tissue are denoted by ** $(p<0.01)$. UCP3, uncoupling protein 3. 


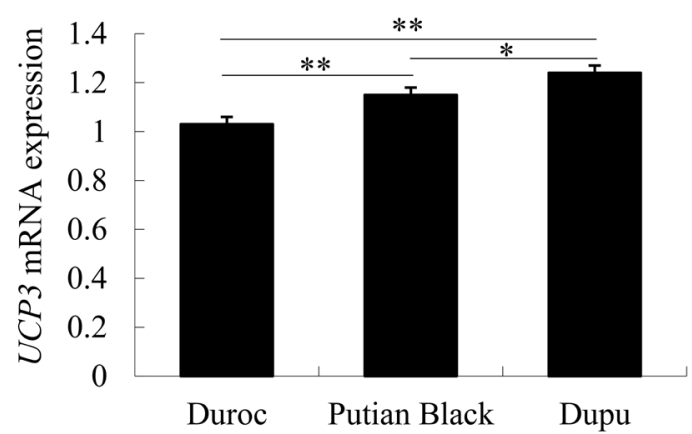

Figure 4. Differentiation of UCP3 mRNA expression in skeletal muscle between different pig breeds. Values are means with their standard errors. Significant differences between breeds are denoted by $\left.{ }^{*} p<0.05\right)$, * $p<0.01$. UCP3, uncoupling protein 3.

\section{DISCUSSION}

It is well known that $U C P 3$ is an important candidate gene for regulating intramuscular fat to affect meat quality traits $[13,14]$. Putian Black pig, which is one of the native breeds in Fujian province, is famous for its meat fragrance and taste. We measured the UCP3 promoter methylation and mRNA expression in the adipose tissue and skeletal muscle of Putian Black pig at three ages. The results showed that the methylation level in the skeletal muscle of the 90-day-old Putian Black pig was lower than that of the other two ages. Even though the changing of methylation status existed in the adipose tissue, it did not reach the statistical significance level. Similarly, the UCP3 mRNA expression level only differed in skeletal muscle at various stages. These findings were consistent with the research that UCP3 mRNA in adipose tissue was similar between Meishan and commercial sows at different postnatal ages, and the expression in skeletal muscle was greater on day 7 in commercial sows $(\mathrm{p}<0.05)$ [2].

In contrast, it has been reported that $u c p 3 \mathrm{mRNA}$ was highly expressed in the brown adipose tissue (BAT) of rats soon after birth, decreased until three months, and recovered thereafter [23]. Pigs however, are one of the few species so far found to lack functional BAT [24], because the functional uncoupling protein 1 was lost in pigs in a genetic event [25]. We suspected that the lack of functional BAT in pigs is responsible for the undifferentiated expression of UCP3 gene in their adipose tissue.

Furthermore, we compared the gene expression level and promoter methylation status of UCP3 in the skeletal muscle of 90-day-old Putian Black pig, Duroc and their crossing progenies (Dupu). The methylation level in Dupu was lower than that in Duroc $(\mathrm{p}<0.05)$, and there was no significant difference in Dupu and Putian Black pig. The expression level of UCP3 gene was higher in Dupu and Putian Black pig than that in Duroc. Another study also suggested that breed can affect the methylation of UCP3 in chicken breast muscle [26].
In the previous work, we found that the pork flavor of Dupu and Putian Black was better than that of Duroc, as Dupu and Putian Black had higher concentrations of saturated and monounsaturated fatty acids and lower concentrations of polyunsaturated fatty acids than Duroc [27]. Therefore, the different expression of UCP3 gene in different pig breeds may be related to meat quality. Interestingly, two novel SNPs $(-882 \mathrm{~A} / \mathrm{T}$, $-852 \mathrm{G} / \mathrm{A}$ ) were detected in the various pig species. Further research is needed to determine whether the allelic variations of UCP3 gene will affect meat quality.

Studies have shown that the methylation of CpG islands in the promoter region played a vital role in gene regulation, cell differentiation, embryonic development, and so on [28-30]. In the skeletal muscle, the methylation of UCP3 promoter experienced a dynamic process, with the development of Putian Black pig, which agreed with the fluctuating trend of UCP3 expression. Meanwhile, breed has a significant influence on the expression of $U C P 3$ via the distinctive methylation status of $\mathrm{CpG}$ island. This indicates that methylation of the CpG island suppresses UCP3 gene expression.

In summary, the major findings of the present study were the differential influences of porcine breed and postnatal age on CpG methylation and expression of UCP3 gene in skeletal muscle. These results might contribute to studies on the function of UCP3 gene in pig breeding for meat quality.

\section{CONFLICT OF INTEREST}

We certify that there is no conflict of interest with any financial organization regarding the material discussed in the manuscript.

\section{ACKNOWLEDGMENTS}

This work was supported by Special Fund for Science and Technology Innovation of Fujian Agriculture and Forestry University (CXZX2017055), Basic Research of the Ministry of Science and Technology of China (2014FY120800), College Students' Innovation and Entrepreneurship Project (201710 389230).

\section{REFERENCES}

1. Park H-S, Min B, Oh S-H. Research trends in outdoor pig production - A review. Asian-Australas J Anim Sci 2017;30: 1207-14.

2. Mostyn A, Litten JC, Perkins KS, et al. Influence of genotype on the differential ontogeny of uncoupling protein 2 and 3 in subcutaneous adipose tissue and muscle in neonatal pigs. J Endocrinol 2004;183:121-31.

3. Monziols A, Bonneau A, Davenel A, Kouba M. Tissue distribution in pig carcasses exhibiting large differences in their 
degree of leanness, with special emphasis on intermuscular fat. Livest Prod Sci 2005;97:267-74.

4. Suzuki K, Ishida M, Kadowaki H, et al. Genetic correlations among fatty acid compositions in different sites of fat tissues, meat production, and meat quality traits in Duroc pigs. J Anim Sci 2006;84:2026-34.

5. Seifert EL, Bezaire V, Estey C, Harper M-E. Essential role for uncoupling protein-3 in mitochondrial adaptation to fasting but not in fatty acid oxidation or fatty acid anion export. J Biol Chem 2008;283:25124-31.

6. Himms-Hagen J, Harper ME. Physiological role of UCP3 may be export of fatty acids from mitochondria when fatty acid oxidation predominates: an hypothesis. Exp Biol Med 2001; 226:78-84.

7. Werner P, Neuenschwander S, Stranzinger G. Characterization of the porcine uncoupling proteins 2 and 3 (UCP2 \& UCP3) and their localization to chromosome $9 \mathrm{p}$ by somatic cell hybrids. Anim Genet 1999;30:221-4.

8. Damon M, Vincent A, Lombardi A, Herpin P. First evidence of uncoupling protein-2 (UCP-2) and -3 (UCP-3) gene expression in piglet skeletal muscle and adipose tissue. Gene 2000; 246:133-41.

9. Katsumata M, Matsumoto M, Kawakami S, Kaji Y. Effect of heat exposure on uncoupling protein-3 mRNA abundance in porcine skeletal muscle. J Anim Sci 2004;82:3493-9.

10. Mostyn A, Litten JC, Perkins KS, et al. Influence of size at birth on the endocrine profiles and expression of uncoupling proteins in subcutaneous adipose tissue, lung, and muscle of neonatal pigs. Am J Physiol Regul Integr Comp Physiol 2005;288:R153642.

11. Costford SR, Chaudhry SN, Salkhordeh M, Harper ME. Effects of the presence, absence, and overexpression of uncoupling protein-3 on adiposity and fuel metabolism in congenic mice. Am J Physiol-Endocrinol Metab 2006;290:E1304-12.

12. Lin J, Cao C, Tao C, et al. Cold adaptation in pigs depends on UCP3 in beige adipocytes. J Mol Cell Biol 2017;9:364-75.

13. Cieslak J, Nowacka-Woszuk J, Bartz M, et al. Association studies on the porcine RETN, UCP1, UCP3 and ADRB3 genes polymorphism with fatness traits. Meat Sci 2009;83:551-4.

14. Li H, Brahi OHD, Zhao X, Xu N, Zhao X. Association of pig UCP3 gene mutations and back fat thickness in the sixth and seventh rib. Mol Biol Rep 2012;39:1823-9.

15. Tu R, Deng C, Xiong Y. Sequencing analysis on partial translated region of uncoupling protein-3 gene and single nucleotide polymorphism associations with the porcine carcass and meat quality traits. Acta Genetica Sinica 2004;31:807-12.

16. Prestridge DS. Predicting Pol II promoter sequences using transcription factor binding sites. J Mol Biol 1995;249:923-32.

17. Knudsen S. Promoter2.0: for the recognition of PolII promoter sequences. Bioinformatics 1999;15:356-61.

18. Reese MG. Application of a time-delay neural network to promoter annotation in the Drosophila melanogaster genome. Comput Chem 2001;26:51-6.

19. Li LC, Dahiya R. MethPrimer: designing primers for methylation PCRs. Bioinformatics 2002;18:1427-31.

20. Kumaki Y, Oda M, Okano M. QUMA: quantification tool for methylation analysis. Nucleic Acids Res 2008;36:W170-5.

21. Erkens T, Van Poucke M, Vandesompele J, et al. Development of a new set of reference genes for normalization of real-time RT-PCR data of porcine backfat and longissimus dorsi muscle, and evaluation with PPARGC1A. BMC Biotechnol 2006;6:41.

22. Livak KJ, Schmittgen TD. Analysis of relative gene expression data using real-time quantitative PCR and the 2(-delta delta C(T)) method. Methods 2001;25:402-8.

23. Oliver P, Pico C, Palou A. Differential expression of genes for uncoupling proteins 1, 2 and 3 in brown and white adipose tissue depots during rat development. Cell Mol Life Sci 2001; 58:470-6.

24. Trayhurn P, Temple NJ, Aerde JV. Evidence from immunoblotting studies on uncoupling protein that brown adipose tissue is not present in the domestic pig. Can J Physiol Pharm 1989;67:1480-5.

25. Berg F, Gustafson U, Andersson L. The uncoupling protein 1 gene $(U C P 1)$ is disrupted in the pig lineage: a genetic explanation for poor thermoregulation in piglets. Plos Genet 2006;2: e129.

26. Gao GL, Wang HW, Zhao XZ, et al. Feeding conditions and breed affect the level of DNA methylation of the mitochondrial uncoupling protein 3 gene in chicken breast muscle. J Anim Sci 2015;93:1522-34.

27. Wu M, Cao C, Zhang L, Xiao T. Contents of fatty acid and amino acid in the muscles of several varieties of pigs (in Chinese). J Fujian Agric For Univ 2009;38:166-70.

28. Laird PW. Principles and challenges of genome-wide DNA methylation analysis. Nat Rev Genet 2010;11:191-203.

29. Antequera F. Structure, function and evolution of $\mathrm{CpG}$ island promoters. Cell Mol Life Sci 2003;60:1647-58.

30. Ehrlich M. Expression of various genes is controlled by DNA methylation during mammalian development. J Cell Biochem 2003;88:899-910. 